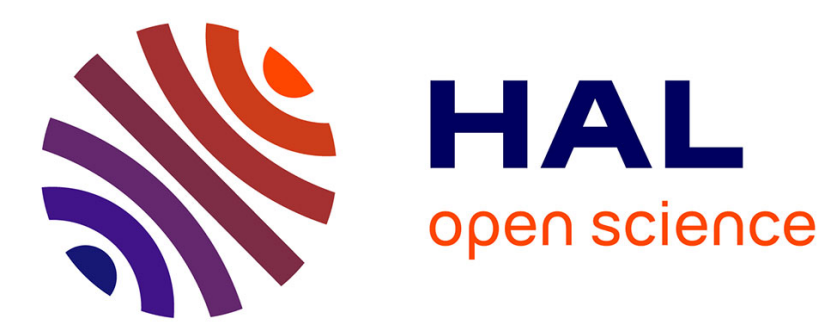

\title{
DNA synthesis-dependent and -independent chromatin assembly pathways in xenopus egg extracts
}

Dominique Ray-Gallet, Geneviève Almouzni

\section{To cite this version:}

Dominique Ray-Gallet, Geneviève Almouzni. DNA synthesis-dependent and -independent chromatin assembly pathways in xenopus egg extracts. Methods in Enzymology, 2004. hal-03048283

\section{HAL Id: hal-03048283 \\ https://hal.science/hal-03048283}

Submitted on 26 Jan 2021

HAL is a multi-disciplinary open access archive for the deposit and dissemination of scientific research documents, whether they are published or not. The documents may come from teaching and research institutions in France or abroad, or from public or private research centers.
L'archive ouverte pluridisciplinaire HAL, est destinée au dépôt et à la diffusion de documents scientifiques de niveau recherche, publiés ou non, émanant des établissements d'enseignement et de recherche français ou étrangers, des laboratoires publics ou privés. 
fact, we have found that yNap1p works well with a broad range of core histones, recombinant or native, from yeast, Drosophila, and Xenopus.

\section{Acknowledgments}

We thank Tomoko Fujii-Nakata for the GST-yNap1p expression plasmid (pTN2) and Shi-Hsiang Shen for $\beta$-glucanase expression plasmid (pUV5-G1S). We also thank Stephanie Abernathy for critical reading of the manuscript. Yeast chromatin work in our laboratory has been supported in part by a Research Grant from the National Science Foundation (MCB9505644) and by a Junior Faculty Research Award from the American Cancer Society awarded to P.J.L.

\section{[8] DNA Synthesis-Dependent and -Independent Chromatin Assembly Pathways in Xenopus Egg Extracts} By Dominique Ray-Gallet and Geneviève Almouzni

\section{Introduction}

In vivo, de novo nucleosome assembly occurs mainly during DNA replication after passage of the replication fork. Parental histones are distributed between daughter strands in a random fashion and a complement of newly synthesized histones must be incorporated to fully duplicate the original chromatin structure. This de novo nucleosome assembly pathway has been studied in powerful biochemical assays that reproduce the coupling of the assembly reaction with DNA synthesis. ${ }^{1}$ A key factor specifically involved in this nucleosome assembly coupled to DNA synthesis is the histone chaperone CAF-1 (chromatin assembly factor-1), which was isolated from nuclear extracts derived from cultured human cells. Its purification was based on its capacity to assemble histone octamers selectively onto newly synthesized DNA, using a plasmid containing the simian virus 40 (SV-40) origin, which can replicate in vitro in the presence of $\mathrm{T}$ antigen. ${ }^{2}$ The CAF-1 complex consists of three evolutionary conserved subunits, $\mathrm{p} 150$, p60, and $\mathrm{p} 48$, which are associated with newly synthesized histones $\mathrm{H} 3$ and $\mathrm{H} 4$ to facilitate their deposition on DNA during replication. ${ }^{3}$ Moreover, CAF-1 is also implicated in nucleosome assembly coupled to

${ }^{1}$ P. D. Kaufman and G. Almouzni, in "Chromatin Structure and Gene Expression" (S. C. R.

Elgin and J. L. Workman, eds.), p. 24. Oxford University Press, New York, 2000.

${ }^{2}$ S. Smith and B. Stillman, Cell 58, 15 (1989).

${ }^{3}$ A. Verreault, P. D. Kaufman, R. Kobayashi, and B. Stillman, Cell 87, 95 (1996). 
nucleotide excision repair (NER), ${ }^{4}$ a process associated with DNA synthesis to ensure the maintenance of nucleosomal organization after DNA repair. In both cases, the proliferating cell nuclear antigen (PCNA) is required for CAF-1 to be recruited. ${ }^{5,6}$ Thus, a CAF-1-PCNA chromatin assembly pathway can be delineated that is tightly associated with DNA synthesis. ${ }^{7,8}$

Attention has been drawn to other nucleosome assembly pathways that occur independently of DNA synthesis. Theoretically, such pathways could be used to restore chromatin structures after disruptive events that are not associated with DNA synthesis. These chromatin assembly pathways may be involved in the deposition of histone variants, for example, the histone $\mathrm{H} 3$ variants, CENP-A located at centromeric regions, ${ }^{9}$ and $\mathrm{H} 3.3$ synthesized in quiescent $G_{1}$ and $G_{2}$ cells. ${ }^{10}$ For both of these variants, several lines of evidence support deposition outside of the $S$ phase. ${ }^{11-13}$ However, the mechanism and the potential chaperone(s) involved in the deposition of these histone variants are not known. Among the histone chaperones known to date, we focused on HIRA, ${ }^{14}$ the homolog of the two Saccharomyces cerevisiae proteins Hir1p and Hir2p, that are cell cycle-regulated transcriptional repressors of histone gene expression. ${ }^{15,16}$ Using Xenopus egg extracts depleted of HIRA, we found that HIRA is critical in vitro for a nucleosome assembly pathway independent of DNA synthesis. ${ }^{17}$

Thus, two chromatin assembly pathways, dependent on DNA synthesis or independent of it, can be monitored in an in vitro system. To gain insight into their specific features, we determined conditions under which the two pathways can be dissociated. The strategy was to abolish either the

${ }^{4}$ P. H. Gaillard, E. M. Martini, P. D. Kaufman, B. Stillman, E. Moustacchi, and G. Almouzni, Cell 86, 887 (1996).

${ }^{5}$ K. Shibahara and B. Stillman, Cell 96, 575 (1999).

${ }^{6}$ J. G. Moggs, P. Grandi, J. P. Quivy, Z. O. Jonsson, U. Huebscher, P. B. Becker, and G. Almouzni, Mol. Cell. Biol. 20, 1206 (2000).

${ }^{7}$ P. Ridgway and G. Almouzni, J. Cell Sci. 113, 2647 (2000).

${ }^{8}$ J. A. Mello and G. Almouzni, Curr. Opin. Genet. Dev. 11, 136 (2001).

${ }^{9}$ D. K. Palmer, K. O'Day, H. L. Trong, H. Charbonneau, and R. L. Margolis, Proc. Natl. Acad. Sci. USA 88, 3734 (1991).

${ }^{10}$ R. S. Wu, S. Tsai, and W. M. Bonner, Cell 31, 367 (1982).

${ }^{11}$ R. D. Shelby, K. Monier, and K. F. Sullivan, J. Cell Biol. 151, 1113 (2000).

${ }^{12}$ B. Sullivan and G. Karpen, J. Cell Biol. 154, 683 (2001).

${ }^{13}$ K. Ahmad and S. Henikoff, Mol. Cell 9, 1191 (2002).

${ }^{14}$ S. Lorain, J. P. Quivy, F. Monier-Gavelle, C. Scamps, Y. Lecluse, G. Almouzni, and M. Lipinski, Mol. Cell. Biol. 18, 5546 (1998).

${ }^{15}$ V. Lamour, Y. Lecluse, C. Desmaze, M. Spector, M. Bodescot, A. Aurias, M. A. Osley, and M. Lipinski, Hum. Mol. Genet. 4, 791 (1995).

${ }^{16}$ P. W. Sherwood, S. V. Tsang, and M. A. Osley, Mol. Cell. Biol. 13, 28 (1993).

${ }^{17}$ D. Ray-Gallet, J. P. Quivy, C. Scamps, E. M. Martini, M. Lipinski, and G. Almouzni, Mol. Cell 9, 1091 (2002). 
nucleosome assembly associated with DNA synthesis or the nucleosome assembly independent of DNA synthesis by eliminating, respectively, either CAF-1 or HIRA activity. Xenopus egg extracts obtained after high-speed centrifugation, high-speed egg extracts (HSEs), represent a convenient system to study both chromatin assembly pathways. ${ }^{18}$ Large quantities of material can be generated rapidly and the nucleosome assembly mechanisms active in these extracts are also observed in other cell-free systems, including extracts derived from human cells. This conservation of functions is attested by the observation that assembly reactions can be complemented with extracts or proteins derived from different species. ${ }^{19,20}$ Therefore, data gathered in this system can be relevant in a wide range of eukaryotic organisms. We describe here how, in the Xenopus egg extract, it is possible to distinguish between these different chromatin assembly pathways and to analyze their properties.

\section{High-Speed Egg Extract Preparation and Immunodepletion}

For in vitro nucleosome assembly assay and NER, interphasic highspeed egg extracts (HSEs) are prepared. We present here briefly the protocol that we use currently. For details concerning the preparation of various extracts derived from Xenopus eggs, several publications provide further information. ${ }^{21,22}$ Xenopus laevis female frogs are induced to lay eggs with human chorionic gonadotropin hormone (hCG) and eggs are collected in $0.1 \mathrm{M} \mathrm{NaCl}$. Incubation in fresh $2 \%$ cysteine solution (in $0.1 \mathrm{M} \mathrm{NaCl}$ with $\mathrm{pH}$ adjusted to $\mathrm{pH} 7.8$ ) for 3 to 4 min allows removal of the jelly coat. After extensive washes in large volumes of $0.1 \mathrm{M} \mathrm{NaCl}$, the eggs are rinsed in extraction buffer [10 $\mathrm{m} M \mathrm{KOH}-\mathrm{HEPES}(\mathrm{pH} 7.8), 70 \mathrm{mM} \mathrm{KCl}, 5 \%$ sucrose, $0.5 \mathrm{~m} M$ dithiothreitol (DTT), and protease inhibitors] and transferred to chilled centrifugation tubes. Excess buffer is removed to avoid dilution of the extract and tubes are subjected to low-speed crushing at $10,000 \mathrm{~g}$ for $30 \mathrm{~min}$ at $4^{\circ}$. After centrifugation three layers are visible. The middle ooplasmic layer is collected by inserting a glass Pasteur pipette through the upper yellow lipid layer. This material is then clarified by ultracentrifugation at $150,000 \mathrm{~g}$ for $1 \mathrm{~h}$ at $4^{\circ}$ (in ultraclear tubes; Beckman, Fullerton,

${ }^{18}$ G. Almouzni and M. Mechali, EMBO J. 7, 665 (1988).

${ }^{19}$ R. T. Kamakaka, M. Bulger, P. D. Kaufman, B. Stillman, and J. T. Kadonaga, Mol. Cell. Biol. 16, 810 (1996).

${ }^{20}$ J. P. Quivy, P. Grandi, and G. Almouzni, EMBO J. 20, 2015 (2001).

${ }^{21}$ A. W. Murray, in "Methods in Cell Biology" (B. K. Kay and H. B. Peng, eds.), p. 581. Academic Press, San Diego, CA, 1991.

${ }^{22}$ G. Almouzni, in "Chromatin: A Practical Approach," p. 195. Oxford University Press, New York, 1998. 
CA). A syringe with a needle is used to pierce the tube and recover the clear ooplasmic fraction, aliquots of which are frozen in liquid nitrogen and stored at $-80^{\circ}$. In general, we obtain a yield of about 3 to $5 \mathrm{ml}$ of extract from three injected frogs. For each new HSE preparation, the following parameters are measured in order to ensure a reproducible quality of the extract: (1) the protein concentration, by the Bradford method, ${ }^{23}$ usually about $40 \mathrm{mg} / \mathrm{ml}$; (2) the ionic strength, using a conductivity meter (MeterLab CDM210; Radiometer Analytical, Lyon, France), which gives an equivalent of 60 to $70 \mathrm{~m} M$ salt; and (3) the chromatin assembly activity, by performing nucleosome assembly followed by supercoiling assay (described below) or micrococcal nuclease digestion (not described here). ${ }^{24,25}$ An aliquot of $10 \mu \mathrm{l}$ of a standard HSE can fully assemble $150 \mathrm{ng}$ of a $3.2-\mathrm{kb}$ plasmid in $3 \mathbf{h}$.

We use an immunodepletion strategy to remove either HIRA or p150 (the large subunit of the CAF-1 complex) from HSE (see Fig. 1A). We thus generate p150-depleted HSE, which is competent only for DNA synthesisindependent chromatin assembly, and HIRA-depleted HSE, which is competent only for DNA synthesis-dependent chromatin assembly. To immunodeplete the chosen protein from HSE, we select antibodies that are both highly specific and efficient in immunoprecipitation. We obtain specific rabbit polyclonal anti-HIRA and anti-p150 antisera by immunization with recombinant Xenopus HIRA and p150 proteins, respectively. ${ }^{17,20}$ For immunodepletion, antibodies are first bound to a solid-phase matrix, which is then mixed with the extract to deplete the protein of interest. In a typical immunodepletion protocol, equal volumes of protein A-Sepharose slurry (CL-4B; Amersham Biosciences, Piscataway, NJ) and serum (anti-p150 or anti-HIRA) are mixed and incubated on a rotating wheel at $4^{\circ}$ for 2 to $3 \mathrm{~h}$. The bound IgG/protein A-Sepharose beads are collected by centrifugation at $5000 \mathrm{~g}$ for $1 \mathrm{~min}$, and a 10 -fold volume of phosphate-buffered saline (PBS) is used to wash the beads by inverting the tube several times. This washing step is repeated four times; the PBS is then eliminated carefully to leave the bound IgG/protein A-Sepharose beads in a minimal volume in order to avoid dilution of the extract to be depleted. Equal volumes (usually $200 \mu \mathrm{l}$ ) of HSE and $\mathrm{IgG} /$ protein A-Sepharose are mixed and incubated on a rotating wheel at $4^{\circ}$ for 1 to $2 \mathrm{~h}$. After centrifugation as described above, the supernatant corresponding to the depleted HSE is collected, frozen in liquid nitrogen, and stored at $-80^{\circ}$ in

\footnotetext{
${ }^{23}$ M. M. Bradford, Anal. Biochem. 72, 248 (1976).

${ }^{24}$ P. H. Gaillard, D. Roche, and G. Almouzni, in "Methods in Molecular Biology" (P. B. Becker, ed.), p. 231. Humana Press, Totowa, NJ, 1999.

${ }^{25}$ J. G. Moggs and G. Almouzni, Methods Enzymol. 304, 333 (1999).
} 
A
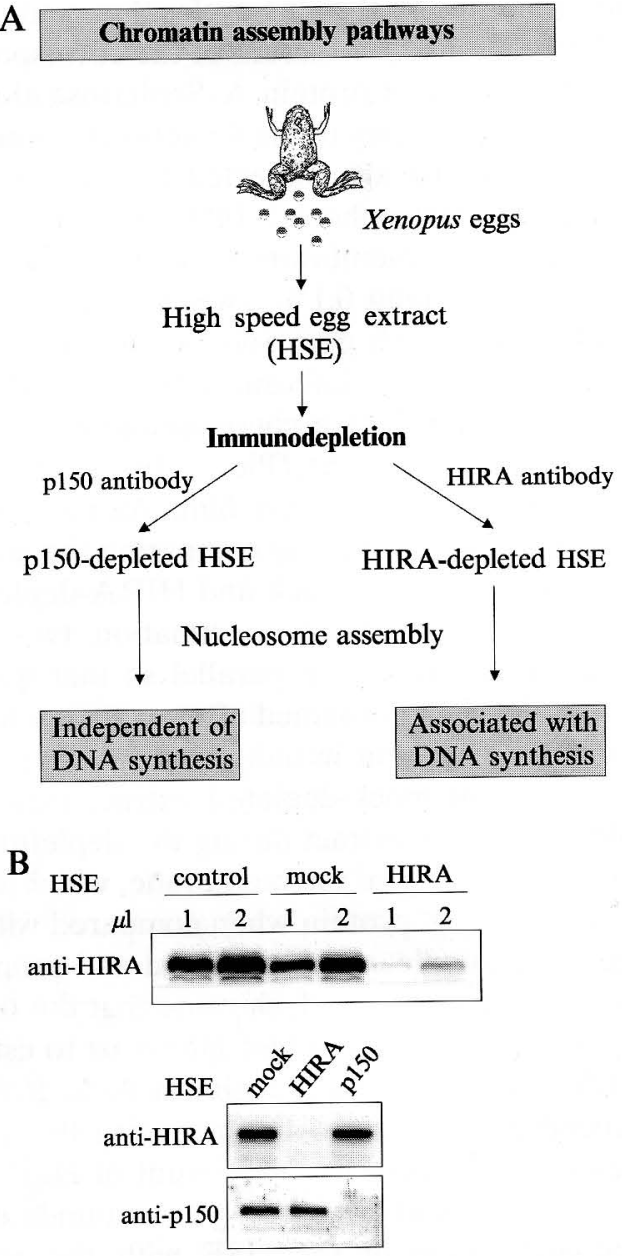

FIG. 1. Two distinct chromatin assembly pathways: one associated with DNA synthesis and CAF-1 mediated, and another uncoupled from DNA synthesis and HIRA dependent. (A) Immunodepletion strategy used to monitor these two distinct chromatin assembly processes individually. Xenopus high-speed egg extracts (HSEs), supporting both pathways, were depleted either of the 150 subunit of CAF- 1 or of HIRA by using antibodies against Xenopus p150 or HIRA, respectively. p150-depleted HSE supports nucleosome assembly independently of DNA synthesis whereas HIRA-depleted HSE supports only synthesisdependent assembly. (B) Analysis of immunodepleted HSE. Top: Two amounts (1 and $2 \mu \mathrm{l})$ of control HSE, mock HSE, or HIRA-depleted HSE were analyzed by Western blotting using anti-Xenopus HIRA antibody. Bottom: $1-\mu 1$ samples of mock, HIRA, or p150-immunodepleted HSE were analyzed by Western blotting using anti-Xenopus HIRA or p150 antibodies. 
aliquots to avoid multiple freeze-thawing cycles that could affect the HSE activity. As controls, the preimmune serum of the corresponding antibody bound to protein A-Sepharose or protein A-Sepharose alone is used for a mock HSE depletion. The efficiency of the depletion is monitored by Western blotting. Briefly, the HSEs are subjected to sodium dodecyl sulfate (SDS)-polyacrylamide gel electrophoresis (aliquots of 0.5 to $2 \mu \mathrm{l}$ ), electrotransferred on a nitrocellulose membrane, and then incubated with a primary antibody in PBS containing $0.1 \%$ Tween 20 and 5\% nonfat milk. After incubation with horseradish peroxidase-conjugated secondary antibody (Jackson ImmunoResearch Laboratories, West Grove, PA), the immune complexes are revealed by a chemiluminescence reaction, using a SuperSignal substrate detection kit (Pierce Biotechnology, Rockford, IL) and visualized by exposure to X-ray film. As illustrated in Fig. 1B (top), the HIRA depletion is analyzed by comparing the amount of HIRA protein in control HSEs and in the mock and HIRA-depleted extracts by Western blotting. For a semiquantitative estimation, two aliquots (1 and $2 \mu \mathrm{l})$ of the different HSEs are run in parallel so that we can ensure at the detection step that the signal obtained after exposure to X-rays is proportional to the amount of protein initially loaded. Note that we usually detect slightly less HIRA in mock-depleted extract than in the control HSE because of dilution of the extract during the depletion process. This is supported by Ponceau staining of the membrane, which shows a general decrease in the total amount of protein when compared with control HSE (not shown). In the HIRA-depleted extract, faint and proportional bands for HIRA are observed with 1 and $2 \mu \mathrm{l}$, showing that the depletion is successful. This semiquantitative Western blot allows us to estimate that the efficiency of the HIRA depletion reaches almost $90 \%$. If the depletion is incomplete, the procedure is modified by increasing the amount of antibody/protein A-Sepharose relative to the amount of HSE. This has been found to be more effective than performing two rounds of depletion or increasing the incubation time of the HSE with the antibody/protein A-Sepharose. These latter methods generally lead to a decrease in the nucleosome activity of the extract. In Fig. 1B (bottom) the depletion of both HIRA and p150 from HSEs is analyzed by Western blotting with anti-HIRA and anti-p150 antibodies. The amounts of both proteins are largely decreased in their respective depleted extracts. In contrast, HIRA is present at a similar level in mock and p150-depleted HSEs and, conversely, the amount of p150 is the same in mock and HIRA-depleted extracts. This shows that the depletion is specific. The use of antibodies directed against other proteins present in the extract also helps to assess whether the depletion process affects the amount of other proteins in the HSE. In particular, when concerned with nucleosome formation, it is 
important to examine whether the amounts of other known histone chaperones such as nucleoplasmin, N1/N2, and Asf1, and also of histones, are affected by the HIRA/CAF-1 depletions. ${ }^{17}$

\section{In Vitro Nucleosome Assembly Assays}

The two chromatin assembly pathways can be monitored by in vitro nucleosome assembly assays using a 3.2-kb circular plasmid pBS (Stratagene, La Jolla, CA) that is UV irradiated or not UV irradiated, and the size of which allows a simple resolution of topoisomers by gel electrophoresis (see Fig. 2A). To monitor the nucleosome assembly pathway independent of DNA synthesis, we use this pBS plasmid with no lesion induced (named p 0). To monitor the CAF-1-dependent assembly pathway associated with DNA synthesis, we use an assay analyzing concomitantly NER and nucleosome assembly. ${ }^{4}$ The pBS plasmid is damaged by UV-C (named $p \mathrm{UV}$ ), which creates two major DNA lesions [cyclobutane pyrimidine dimers and (6-4) photoproducts] that are both repaired by NER pathway. Here, the pBS plasmid DNA is prepared with a Qiagen (Chatsworth, CA) plasmid purification kit. The UV-damaged plasmid is created by using a germicidal lamp (wavelength, $254 \mathrm{~nm}$ ). The height of the lamp is adjusted to obtain the desired UV fluence rate measured with a Latarjet dosimeter. A dose of $100 \mathrm{~J} / \mathrm{m}^{2}$ induces one pyrimidine dimer photoproduct in $1000 \mathrm{bp}$ [about 0.75 cyclobutane pyrimidine dimer and 0.25 (6-4) photoproduct]. ${ }^{26}$ The dose usually used in our assays is $500 \mathrm{~J} / \mathrm{m}^{2}$, resulting in intense signals for the repair synthesis compared with nondamaged DNA.

The assembly reaction is performed as follows. In a final volume of $25 \mu \mathrm{l}, 10 \mu \mathrm{l}$ of HSE (depleted or mock depleted) is added to $150 \mathrm{ng}$ of $\mathrm{p}$ 0 or $\mathrm{p} \mathrm{UV}$ in a reaction buffer containing $5 \mathrm{mM} \mathrm{MgCl} 2,40 \mathrm{~m} M$ HEPES$\mathrm{KOH}$ ( $\mathrm{pH} 7.8$ ), $0.5 \mathrm{~m} M$ DTT, $4 \mathrm{mM}$ ATP, $40 \mathrm{~m} M$ phosphocreatine, $2.5 \mu \mathrm{g}$ of creatine phosphokinase and $5 \mu \mathrm{Ci}$ of $\left[\alpha^{32} \mathrm{P}\right] \mathrm{dCTP}$ in order to monitor the repair synthesis. The reaction is incubated for $3 \mathrm{~h}$ at $23^{\circ}$ and stopped by adding $25 \mu \mathrm{l}$ of stop mix ( $30 \mathrm{mM}$ EDTA, $0.7 \% \mathrm{SDS}$ ). The nucleosome assembly reaction is then monitored by a supercoiling assay allowing analysis of the topological forms of the plasmid after protein extraction by agarose gel electrophoresis. The circular plasmid, when incubated in HSEs, undergoes conformational changes corresponding to the progressive deposition of nucleosomes while the topoisomerase activity allows the absorption of the constraints. After deproteinization, topoisomers with an increasing number of negative supercoils reflect the extent of assembly. The stopped nucleosome assembly reaction is completed to

${ }^{26}$ R. D. Wood, M. Biggerstaff, and M. K. K. Shivji, Methods 7, 163 (1995). 
$100 \mu \mathrm{l}$ with $\mathrm{H}_{2} \mathrm{O}$, and incubated with $10 \mu \mathrm{g}$ of DNase-free RNase A for $45 \mathrm{~min}$ at $37^{\circ}$ and with $20 \mu \mathrm{g}$ of proteinase $\mathrm{K}$ for $1 \mathrm{~h}$ at $37^{\circ}$. After protein extraction with phenol-chloroform-isoamyl alcohol $(25: 24: 1$, v/v), the DNA in the aqueous phase is precipited by adding $100 \mu \mathrm{l}$ of $5 \mathrm{M}$ ammonium acetate and $250 \mu \mathrm{l}$ of ethanol in the presence of glycogen $(2 \mu \mathrm{g})$ as carrier and subjected to centrifugation at $20,000 \mathrm{~g}$ for $30 \mathrm{~min}$ at $4^{\circ}$. The pellet is washed with $70 \%$ ethanol, dried, and then resuspended in $16 \mu \mathrm{l}$ of TE [10 $\mathrm{m} M$ Tris- $\mathrm{HCl}$ (pH 7.5), $1 \mathrm{mM}$ EDTA (pH 8)] and $4 \mu \mathrm{l}$ of 5x loading buffer $(0.42 \%$ bromphenol blue, $50 \%$ glycerol $)$. Generally, half $(10 \mu \mathrm{l})$ is loaded on a $1 \%$ agarose gel in TAE $1 \times$ buffer $(40 \mathrm{mM}$

$\mathbf{A}$ Nucleosome assembly assay

Associated with DNA synthesis

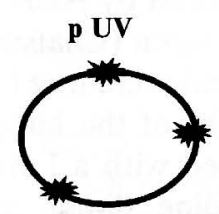

\begin{tabular}{c|l}
$\begin{array}{c}\text { Repair synthesis } \\
\text { and } \\
\text { Nucleosome } \\
\text { assembly }\end{array}$ & + HSE \\
& $+\alpha-32 \mathrm{P}] \mathrm{dCTP}$
\end{tabular}

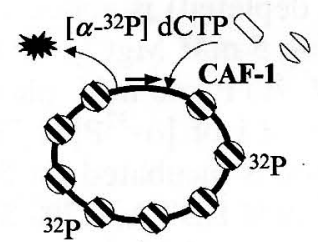

Supercoiling assay

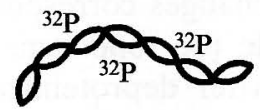

Assembled repaired (labeled) plasmid

\section{Independent of DNA synthesis}
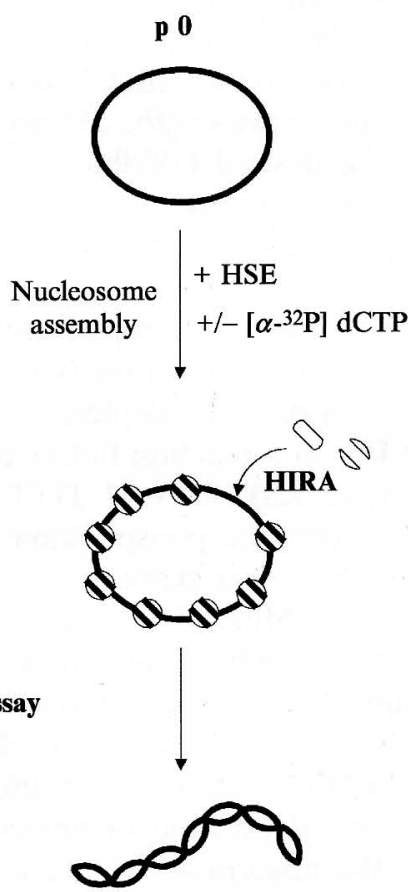

Assembled non-repaired (unlabeled) plasmid

FIG. 2. (continued) 


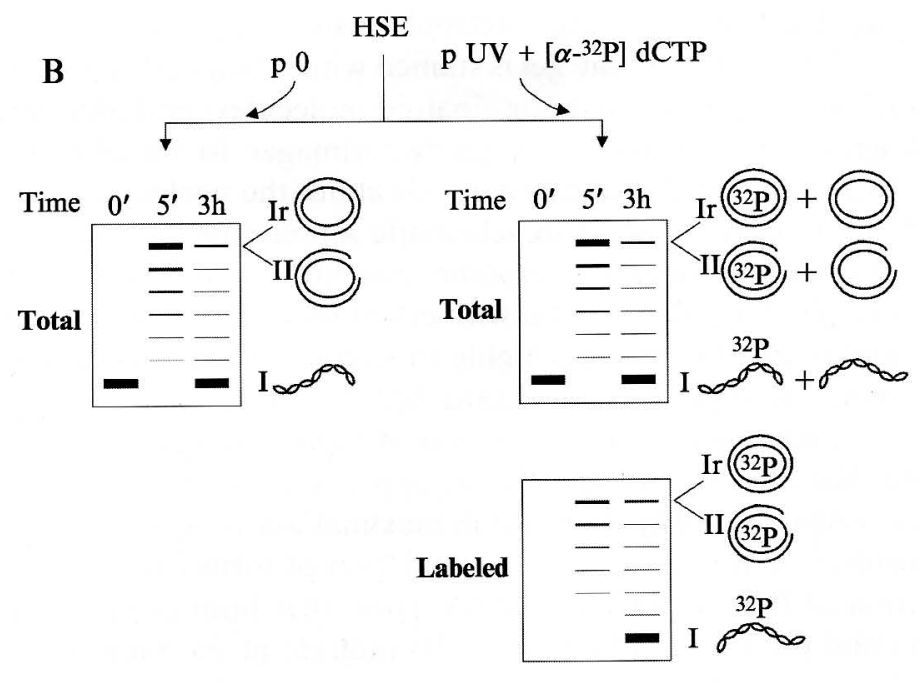

C

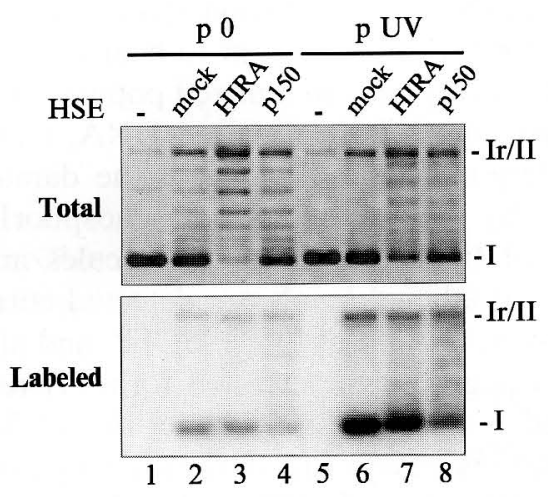

FIG. 2. DNA synthesis-dependent or -independent nucleosome assembly assays. (A) To examine chromatin assembly associated with DNA synthesis (mediated by CAF-1), the NERcoupled nucleosome assembly pathway was used. UV-irradiated plasmid (p UV) was incubated with HSE in the presence of $\left[\alpha^{3}{ }^{32}\right.$ p]dCTP and the nucleosome assembly on repaired (labeled) DNA was analyzed by supercoiling assay and autoradiography. To examine nucleosome assembly independent of DNA synthesis (HIRA dependent), nonirradiated plasmid ( $p 0$ ) was incubated with HSE. The nucleosome assembly of the nonrepaired (unlabeled) DNA was analyzed by supercoiling assay and visualized by ethidium bromide staining. (B) Schematic representation of supercoiling gel analysis. After nucleosome assembly, the plasmid DNA is deproteinized and analyzed by agarose gel electrophoresis. For a nucleosome assembly assay with HSE and nonirradiated plasmid (p 0), the DNA is visualized by ethidium bromide staining (total DNA). For a nucleosome assembly assay with HSE and UV-irradiated plasmid (p UV) in the presence of $\left[\alpha^{32}\right.$ p]dCTP, the repaired DNA is visualized by autoradiography or phosphoimaging (labeled DNA). Migration positions of 
Tris-acetate, $1 \mathrm{~m} M$ EDTA) and electrophoresis performed at $1.5 \mathrm{~V} / \mathrm{cm}$ for $20 \mathrm{~h}$ at $4^{\circ}$. After migration, the gel is stained with ethidium bromide to visualize total DNA (repaired and nonrepaired molecules) and then dried and autoradiographed or analyzed by phosphorimager to visualize only the labeled, (repaired) DNA (for more details about the nucleosome assembly protocol, see Gaillard $\mathrm{et} \mathrm{al}^{24}$ ). A schematic representation of supercoiling gels resulting from these nucleosome assembly assays is presented in Fig. 2B. For $\mathrm{p} 0$, the gel is stained with ethidium bromide to visualize total DNA. Input plasmid (time 0) is highly supercoiled (fast migrating form I). After $5 \mathrm{~min}$, the supercoiled plasmid becomes relaxed (slow migrating form Ir) as a consequence of the action of topoisomerases present in the HSE, and then progressive supercoiling appears, corresponding to progressive nucleosome assembly. In general, maximal assembly is achieved after $3 \mathrm{~h}$ of incubation, leading to the accumulation of form I corresponding to the position of fully supercoiled DNA. Note that both the relaxed DNA form (Ir) and the nicked DNA form (II) migrate at the same position on these gels. For p UV, staining of the gel with ethidium bromide allows one to visualize total DNA, the migration profile of which is comparable to that observed with $\mathrm{p} 0$. It is important to bear in mind that in the case of $p \mathrm{UV}$, total DNA corresponds to a mixed population of molecules containing repaired (labeled) and nonrepaired DNA, and in these extracts only a fraction corresponding to $10-15 \%$ of the damaged plasmid molecules is repaired. ${ }^{27}$ By autoradiography or PhosphorImager analysis of the gel, only repaired (labeled) plasmid molecules are revealed. After $5 \mathrm{~min}$ of reaction, faint labeled bands are detected corresponding to first repair events with incorporation of $\left[\alpha^{-}{ }^{32} \mathrm{P}\right] \mathrm{dCTP}$, and after $3 \mathrm{~h}$ there is an accumulation of fast-migrating supercoiled form (I) resulting from both completed repair and nucleosome assembly of the p UV plasmid.

Nucleosome assembly assays are performed by combining each depleted extract (mock, HIRA, and p150) with either nonirradiated plasmid (p 0) or UV-C-irradiated plasmid (p UV) in the presence of $\left[\alpha^{32} \mathrm{P}\right] \mathrm{dCTP}$

${ }^{27}$ P. H. Gaillard, J. G. Moggs, D. M. Roche, J. P. Quivy, P. B. Becker, R. D. Wood, and G. Almouzni, EMBO J. 16, 6281 (1997).

DNA plasmid form I (supercoiled), form II (nicked circular), and form Ir (relaxed, closed circular) are indicated. (C) Analysis of the nucleosome assembly activities in HIRA- and p150-depleted HSEs. Mock, HIRA-depleted, or p150-depleted HSEs were used in nucleosome assembly assays that were carried out over $3 \mathrm{~h}$ in the presence of $\left[\alpha^{-32} \mathrm{p}\right] \mathrm{dCTP}$ with $150 \mathrm{ng}$ of either nonirradiated plasmid ( $p 0$ ) or UV-C-treated plasmid ( $p$ UV). Nucleosome assembly was analyzed by supercoiling assay as described above. Input DNA run in parallel (lanes 1 and 5) and migration positions of DNA plasmid forms are indicated. 
to monitor the repaired labeled DNA. After $3 \mathrm{~h}$ of incubation, the topological form of the plasmid DNA, obtained in each nucleosome assembly reaction, is analyzed by supercoiling assay (Fig. 2C). The p150-depleted HSE, like mock-depleted HSE, supports efficient nucleosome assembly on unirradiated DNA (p 0); indeed, the plasmid molecules become almost completely supercoiled (form I) (Fig. 2C, total DNA, lanes 2 and 4). With HIRA-depleted HSE, only a few supercoiled DNA molecules are observed and DNA is present mostly as the relaxed form (Ir), indicating that this synthesis-independent nucleosome assembly reaction is impaired (Fig. 2C, total DNA, lane 3). Note that by autoradiography, faint supercoiled labeled bands are observed with $\mathrm{p} 0$ in each depleted HSE (Fig. 2C, labeled DNA, lanes 2-4). This corresponds to a low level of background incorporation on the nonirradiated $\mathrm{p} 0$, essentially due to the presence of residual nicks in the plasmid preparation, which can promote PCNA-CAF-1dependent assembly. ${ }^{25}$ Therefore, HIRA-depleted HSE fails to support nucleosome assembly on nondamaged DNA as opposed to p150-depleted HSE, which remains efficient in this nucleosome assembly pathway. In contrast, HIRA-depleted HSE, as well as mock-depleted extract, support efficient assembly on UV-irradiated plasmid ( $p$ UV), labeled DNA molecules being mainly supercoiled (Fig. 2C, labeled DNA, lanes 6 and 7). With p150depleted HSE, a low level of supercoiled repaired DNA and a higher level of relaxed repaired DNA are observed (Fig. 2C, labeled DNA, lane 8), showing that this extract is unable to assemble nucleosomes coupled to NER. The amount of supercoiled plasmid visualized by ethidium bromide (Fig. 2C, total DNA, lane 8) is nevertheless almost unchanged as compared with the reaction with p 0 (Fig. 2C, total DNA, lane 4) and corresponds to nonrepaired molecules. We conclude that p150-depleted HSE fails to support nucleosome assembly coupled to DNA repair whereas HIRA-depleted HSE retains this activity.

In conclusion, with HIRA- and p150-depleted HSEs, we effectively gain access to extracts that are competent, respectively, only for the chromatin assembly pathway associated with DNA synthesis (coupled to NER) or only for the assembly pathway independent of DNA synthesis.

\section{Control Experiments for Nucleosome Assembly with Depleted HSE Analyzed by Supercoiling Assays}

To draw valid conclusions in these nucleosome assembly assays with depleted extracts, important control experiments are necessary. One is to ensure that the depleted extract retains its topoisomerase activity which is essential to follow assembly of nucleosomes. This can be easily verified by analyzing the topological form of the plasmid at an early time point in 
A

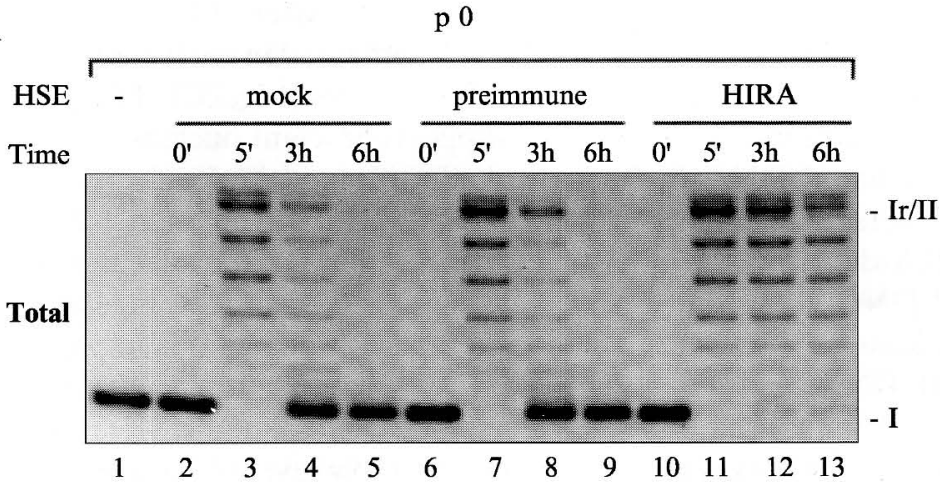

B

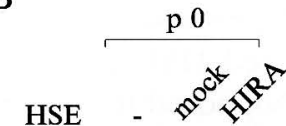

HSE

Total

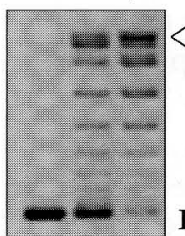<smiles>[In]</smiles><smiles>c1ccccc1</smiles>
II<smiles>c1ccccc1</smiles>

Total

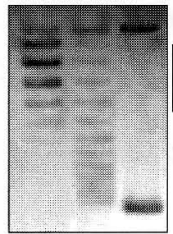

II

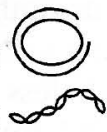

Ir

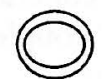

C

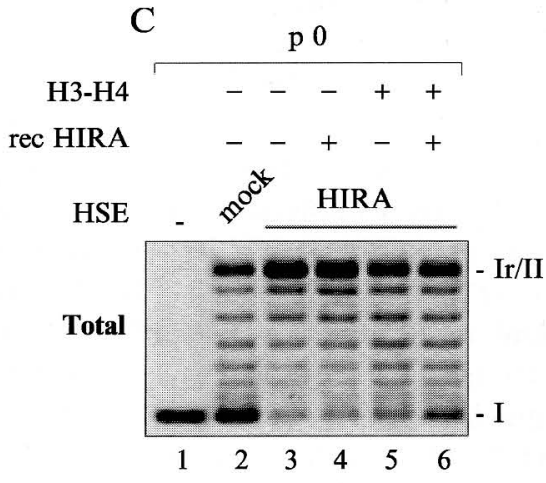

+ chloroquine

Fig. 3. Control experiments involving nucleosome assembly with depleted HSE. (A) Time course analysis of nucleosome assembly with mock, preimmune, or HIRA-depleted HSE. Nucleosome assembly assays were carried out with nonirradiated plasmid p 0 (150 ng) and either mock, preimmune, or HIRA-depleted HSE. The nucleosome assembly reactions were processed for supercoiling assay after $0 \mathrm{~min}, 5 \mathrm{~min}, 3 \mathrm{~h}$, or $6 \mathrm{~h}$ of incubation. After electrophoresis on agarose gels, DNA was visualized by ethidium bromide (total DNA). Input p 0 DNA run in parallel (lane 1) and the migration positions of the different plasmid forms are indicated as in Fig. 2B. (B) Nucleosome assembly assays, with nonirradiated plasmid p 0 $(150 \mathrm{ng})$ and with mock or HIRA-depleted HSE, were analyzed after $3 \mathrm{~h}$ of incubation by supercoiling assay. Agarose gel electrophoresis was performed in the presence or in the absence of chloroquine $(10 \mu \mathrm{g} / \mathrm{ml})$ and DNA was visualized by ethidium bromide (total DNA). The input DNA run in parallel and the migration positions of the different plasmid forms are indicated in Fig. 2B. (C) Significant rescue of nucleosome assembly activity of HIRA-depleted HSE by the addition of both HIRA and (H3-H4) $)_{2}$ tetramers. Recombinant Xenopus HIRA (rec HIRA) or (H3-H4) 2 tetramers or both were added to the nucleosome assembly reaction mix with HIRA-depleted HSE and p 0 (150 ng). A nucleosome assembly 
the chromatin assembly reaction. As shown in Fig. 3A, we have observed that, after $5 \mathrm{~min}$ of incubation, the supercoiled plasmid becomes relaxed similarly in mock, preimmune, or HIRA-depleted HSEs, indicating that the depletions do not affect the topoisomerase activity (lanes 3, 7, and 11). It is also important to test longer chromatin assembly incubation times to determine whether the defect in the assembly reaction observed at $3 \mathrm{~h}$ remains after a longer incubation time and that the decrease in assembly is not just the consequence of a slower activity of the depleted extract. For HIRA-depleted extract, we showed no increase in supercoiled plasmid even after $6 \mathrm{~h}$ of incubation (Fig. 3A, compare lanes 12 and 13). Another control experiment is to verify that the plasmid migrating as a Ir/II form is, in fact, a relaxed circular plasmid (form Ir), corresponding to nonassembled DNA, and not a nicked circular plasmid (form II) that could be generated by the presence of nuclease activity gained during the depletion process. One way to address this issue is to perform electrophoresis in a chloroquine-containing agarose gel $(10 \mu \mathrm{g} / \mathrm{ml})$. Chloroquine adds positive supercoils to DNA, and therefore negatively supercoiled plasmids become relaxed and relaxed plasmids migrate as a supercoiled plasmid, whereas nicked circular plasmids still migrate at the same position as in a nonchloroquine gel. By this approach, we show that after $3 \mathrm{~h}$ of nucleosome assembly reaction in the presence of HIRA-depleted HSE, the plasmid DNA recovered is truly in the relaxed form (Ir) and therefore corresponds to nonassembled DNA and not to nicked DNA (Fig. 3B). Finally, it is also important to be able to rescue the defect of the depleted HSE: first, by adding back a small amount of control HSE to be sure that the depletion did not introduce contaminating inhibitory activity, and second, by adding back the protein that was depleted. However, the complementation can be complicated if the serum depletes not only the protein against which it was derived but also associated proteins that could be partners for the nucleosome assembly. For HIRA-depleted HSE, the addition of recombinant HIRA (purified from Escherichia coli, using the Impact T7 purification system; New England BioLabs, Beverly, MA) is not sufficient to rescue the supercoiling activity (Fig. 3C, lane 4). However, we have succeeded in recovering nucleosome assembly by adding back both recombinant Xenopus HIRA and $(\mathrm{H} 3-\mathrm{H} 4)_{2}$ tetramers (purified from chicken erythrocytes ${ }^{28}$ )

${ }^{28}$ R. H. Simon and G. Felsenfeld, Nucleic Acids Res. 6, 689 (1979).

assay with mock-depleted HSE was performed in parallel as a positive control for assembly. The reactions were stopped after $3 \mathrm{~h}$ and analyzed by supercoiling assay, and the DNA was visualized after agarose gel electrophoresis by ethidium bromide staining. DNA input run in parallel and the migration positions of the different plasmid forms are indicated as in Fig. 2B. 
(Fig. 3C, lane 6). These complementation studies are performed in siliconized tubes to circumvent problems related to the sticking feature of histones. Moreover, it is important to preincubate HIRA and (H3-H4) for at least $10 \mathrm{~min}$ on ice and to add this mix in chromatin assembly after $5 \mathrm{~min}$ of reaction at $23^{\circ}$. The addition after $5 \mathrm{~min}$ is crucial to allow the topoisomerases to relax the plasmid; otherwise, the histones could bind directly to the supercoiled DNA and prevent the nucleosome assembly process. The complementation that we observe suggests that HIRA complexed with $(\mathrm{H} 3-\mathrm{H} 4)_{2}$ is necessary to initiate nucleosome assembly. However, the rescue being only partial, we propose that either the recombinant HIRA lacks some posttranslational modifications or some HIRA-codepleted partners are missing to restore a completely efficient nucleosome assembly.

\section{Conclusions and Perspectives}

We describe here an immunodepletion strategy for Xenopus HSE in order to dissociate the DNA synthesis-dependent and -independent chromatin assembly pathways that operate efficiently in these extracts. By depleting p150 (CAF-1 large subunit) we can obtain an HSE competent only for nucleosome assembly independent of DNA synthesis, and by depleting HIRA we can generate a system that is efficient only for DNA synthesis-dependent nucleosome assembly pathway that we analyze by NER. We previously described a specific suppression of synthesisindependent nucleosome assembly in Drosophila preblastoderm embryo extracts. ${ }^{25}$ In that case, this suppression was achieved by increasing the salt in the nucleosome assembly assay, but the biochemical basis of this defect was not fully understood. It is possible that salt can affect the behavior of a critical component in this assembly pathway. With specific immunodepleted HSE, we gain access to an in vitro system allowing the separate investigation of these two chromatin assembly pathways, dependent on or independent of DNA synthesis.

We believe that chromatin assembly operates by an "assembly line" mechanism in which histones are successively transferred between dedicated chaperones before their deposition onto DNA to prevent unwanted interactions of histones due to their charges. It may be possible that the two nucleosome assembly pathways delineated here differ entirely in the makeup of this assembly line or that some components are common between them. An immunodepletion strategy, similar to that described here for CAF-1 and HIRA, can be used for other known histone chaperones in order to determine whether they have a function assigned to one or the other pathway. 


\title{
Acknowledgments
}

We are grateful to Catherine Green for critical reading of the manuscript. This work was supported by la Ligue Nationale contre le Cancer (Equipe Labellisée la Ligue), Euratom (FIGH-CT-1999-00010 and FIGH-CT-2002-00207), the Commissariat à l'Energie Atomique (LRC no. 26), and RTN (HPRN-CT-200-00078 and HPRN-CT-2002-00238).

\section{[9] Preparation of Defined Mononucleosomes, Dinucleosomes, and Nucleosome Arrays In Vitro and Analysis of Transcription Factor Binding}

\author{
By Lisa Ann Cirillo and Kenneth S. Zaret
}

\section{Introduction}

Eukaryotic genes are transcriptionally controlled by regulatory factors bound to promoters and enhancers. Because the eukaryotic genome is assembled into chromatin, it follows that we must understand how regulatory factors function in that context. The repeating structural unit of chromatin is the nucleosome, with 146 bp of DNA wrapped nearly twice around an octamer of the four core histones $\mathrm{H} 2 \mathrm{~A}, \mathrm{H} 2 \mathrm{~B}, \mathrm{H} 3$, and H4. Long arrays of nucleosomes can fold into more compact structures, which in turn are stabilized by the binding of the linker histone $\mathrm{H} 1{ }^{1-3}$ This chapter describes ways to reconstitute nucleosomes and nucleosome arrays with defined DNA sequences, in order to investigate transcription factor interactions and histone modifications in those contexts.

Accessibility of DNA-binding proteins to nucleosomal DNA is contingent on the rotational and translational position of the DNA with respect to the histone octamer. DNA sequence determines the curvature, flexibility, and kinking ability of DNA, which in turn determine overall nucleosome stability and positioning. Although some naturally occurring gene regulatory regions harbor strong rotational and translational nucleosomepositioning sequences, ${ }^{4-6}$ nucleosome positioning most often appears to

${ }^{1}$ C. Tse and J. C. Hansen, Biochemistry 36, 11381 (1997).

${ }^{2}$ L. M. Carruthers, J. Bednar, C. L. Woodcock, and J. C. Hansen, Biochemistry 37, 14776 (1998).

${ }^{3}$ L. M. Carruthers and J. C. Hansen, J. Biol. Chem. 275, 37285 (2000).

${ }^{4}$ H. Richard-Foy and G. L. Hager, EMBO J. 6, 2321 (1987).

${ }^{5}$ E. Verdin, P. Paras, Jr., and C. Van Lint, EMBO J. 12, 3249 (1993).

${ }^{6}$ R. T. Simpson, F. Thoma, and J. M. Brubaker, Cell 42, 799 (1985). 